\title{
Systematic review and meta-analysis of perioperative compilations of hand-sewn esophagojejunostomy used for laparoscopic total gastrectomy
}

Yu-Cheng Zhou ( $\square$ zhouyuchengsrm@126.com )

Research article

Keywords: Totally laparoscopic total gastrectomy, Esophagojejunostomy, Hand-sewn

Posted Date: October 23rd, 2019

DOI: https://doi.org/10.21203/rs.2.16383/v1

License: (c) (i) This work is licensed under a Creative Commons Attribution 4.0 International License. Read Full License 


\section{Abstract}

Background: We examine the perioperative complications of hand-sewn esophagojejunostomy (EJ) methods used for totally laparoscopic total gastrectomy (TLTG) for the treatment of gastric cancer.

Methods: We reviewed PUBMED, EMBASE and the Cochrane Central Register for studies published from May 1998 to May 2018 to evaluate the perioperative complications of hand-sewn esophagojejunostomy applied for TLTG. Five studies were found to meet the inclusion criteria for our meta-analysis. After data extraction and quality assessment, we used Stata 12 to pool the data.

Results: Five studies involving 234 patients were considered in our meta-analysis. The pooled data show an anastomotic leakage value of $1 \%(95 \% \mathrm{Cl} 0$ to $4 \%)$ \an anastomotic stricture value of $1 \%(95 \% \mathrm{Cl} 0$ to $3 \%)$ \a conversion value of 0 and a postoperative bleeding value of $2 \%$ ( $95 \% \mathrm{Cl} 0$ to $6 \%$ ). Conclusions: TLTG involving intracorporeal hand-sewn end-to-side esophagojejunostomy serves as a safe approach to the treatment of gastric cancer. As this method is adopted by professionals, intracorporeally handsewn EJ could become an accepted means of executing widely used laparoscopic procedures of EJ.

\section{Background}

Each year, 990,000 people are diagnosed with gastric cancer worldwide, and 738,000 ultimately die from the disease[1], rendering it the fourth most common form of cancer and the second most common cause of cancer death[2]. The first laparoscopic distal gastrectomy was performed in 1991[3]. Laparoscopic gastrectomy for the treatment of early gastric cancer has been used widely, as it is less invasive than open surgery treatments. Laparoscopic gastrectomies present unique advantages, causing only mild postoperative pain and allowing for rapid recovery to normal bowel functions. However, totally laparoscopic total gastrectomy (TLTG) treatments for gastric cancer have only been performed on a few occasions. Randomized controlled trials and meta-analyses have confirmed that laparoscopic gastrectomies support better postoperative outcomes than those of open surgery, causing less intraoperative blood loss and postoperative pain, requiring a shorter hospital stay, and resulting in decreased levels of morbidity with comparable oncological results[4-6].

The presence of an esophagojejunostomy anastomosis can be technically demanding, limiting the feasibility of the TLTG approach. The creation of an esophagojejunal anastomosis (EJ) after total gastrectomy can be technically difficult, and reconstruction complications such as anastomotic leakages and strictures account for a significant proportion of postoperative morbidity values.

Several reports, including systematic reviews, meta-analyses, and retrospective comparative studies, have compared the EJ tool of the TLTG process. Shim et al.[7] reported on four forms of EJ anastomosis applied after TLTG, which could still not be used to perform a standard EJ anastomosis. Additionally, Zheng et al.[8] performed a meta-analysis comparison of intra-esophagojejunostomy and extraesophagojejunostomy methods. They conclude that an intracorporeal EJ can ensure the same clinical outcomes as an extracorporeal EJ[8]. However, no studies have yet compared different EJ procedures.

The aim of this study was to evaluate the perioperative complications related to hand-sewn esophagojejunostomy used for laparoscopic total gastrectomy. To evaluate the safety of hand-sewn esophagus-jejunostomy methods, we performed a meta-analysis.

\section{Methods}

\section{Search strategy}

Our meta-analysis was performed according to the Preferred Reporting Items for systemic Reviews and meta-analysis (PRISMA) statement. We searched PUBMED, EMBASE and the Cochrane Central Register for relevant studies published in English from May 1998

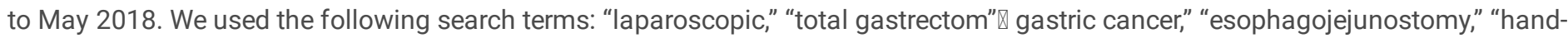
sewn esophagojejunostomy"and "single arm trial." Then, all titles, abstracts, or related citations were scanned and reviewed. We also used combined Boolean operators "AND" or "OR" in the Title/Abstract search field.

Inclusion and exclusion criteria

The two investigators reviewed the articles. The following inclusion criteria were used: articles covering (1) gastric cancer performed via hand-sewn TLTG; (2) single arm trials; and (3) anastomotic leakages, intraluminal bleeding, anastomotic strictures, and open conversion. The following exclusion criteria were applied: (1) case reports, reviews, editorial comments, meeting abstracts and articles without 
applicable data; (2) studies with insufficient data such as missing values and (3) comparative studies. We identified relevant studies as illustrated in Figure 1.

Outcome

Two authors reviewed the relevant studies. Disagreements were resolved by discussion to reach a consensus. The two authors extracted data on anastomotic leakage, intraluminal bleeding, anastomotic stricture, and open conversion. Baseline comparative data, data on clinical outcomes, and data on postoperative complications were also recorded. Table 1 summarizes the baseline characteristics and assessments used.

Statistical analysis

We used Stata 12.0 to perform an analysis of the data. We used Q and $\mathrm{I}^{2}$ (ranges from 0 to $100 \%$ ) statistics to evaluate levels of heterogeneity, with $\mathrm{I}^{2}<50 \%$ and $\mathrm{P}>0.1$ denoting the presence of no significant heterogeneity, and we used fixed-effects model. When $\mathrm{I}^{2}>50 \%$ and $\mathrm{P}<0.1$ denoting the presence of significant heterogeneity, the random effects model was applied.

We used the ES (estimate) and $95 \% \mathrm{Cl}$ to evaluate binary data. The level of statistical significance was set to 0.05 .

\section{Results}

Five studies were considered[9-13]. We obtained these studies as depicted in Figure 1. From the selected databases, 69 studies were obtained. After the screening of titles and abstracts, 29 studies were excluded. After processing, 24 studies were excluded. Finally, five studies were included in our meta-analysis. Table 2 Quality assessment of the included studies

Five studies report on cases of anastomotic leakage. Pooled data on anastomotic leakage account for $1 \%\left(n=243, I^{2}=23.05 \%, p=0.27\right.$, $95 \% \mathrm{Cl} 0$ to $4 \%$, fixed-effects model, Figure 2 ).

Anastomotic stricture was provided in five studies. The pooled data on anastomotic stricture account for $1 \%\left(n=243, \mathrm{I}^{2}=60.95 \%, \mathrm{p}=\right.$ $0.04,95 \% \mathrm{Cl} 0$ to $3 \%$, random-effects model, Figure 3 ).

Data on conversion were available in two studies. The pooled data on conversion account for $0\left(n=136, I^{2}=0, p=0.74\right.$, fixed-effects model, Figure 4).

Two studies report on cases involving postoperative bleeding. The pooled data on conversion account for $2 \%\left(n=156, I^{2}=0, p=0,95 \%\right.$ $\mathrm{Cl} 0$ to $6 \%$, fixed-effects model, Figure 5).

\section{Discussion}

We considered four clinical studies involving a short-term follow-up period.

This meta-analysis was performed to evaluate the hand-sewn EJ approach to TLTG. The present study is the first meta-analysis to evaluate perioperative complications of hand-sewn EJ for TLTG.

Our meta-analysis shows that patients with upper gastric cancer present comparable basic characteristics. Our study compares shortterm follow-up outcomes of patients who have received TLTG. These patients share comparable baseline characteristics.

The postoperative complication rate was found to be high relative to the sample size of the considered group (42.8\% for leakage and $7 \%$ for stenosis)[7]. Another EJ approach described involves using a circular stapler mimicking that of the commonly applied open EJ[14] that involves extending the size of a laparoscopic port to accommodate a stapler. Potential risks of jejunal limb rotation or latero-lateral EJ twisting related to using a linear stapler can levels of increase tension acting on the upper portion of the anastomosis, complicating mediastinum leakage treatment.

Bracale et al.[9] conducted a multicenter study on four patients experiencing anastomotic leakage, accounting for approximately $6 \%$ of patients. This may be associated with the surgical side-to-side anastomosis approach. Three different centers also presented different surgical results. Puntambekar et al.[11] reported an anastomotic leakage value of 0 , consistent with that found in our study. Additionally, Norero et al.[10] reported on a single center study involving 51 patients with gastric cancer who had received TLTG. The surgical process 
applied involved hand-sewn esophagojejunostomy. Two cases of anastomotic leakage resulted (0.36\%). A two-layered anastomosis was introduced using the hand-sewn EJ technique during surgery. For one layered suture, a two layered suture can mitigate anastomosis tension to prevent leakage. An EJ anastomosis allows the surgeon to abandon a purse suture, reducing operation time[10]. Different anastomosis techniques considered may have increased the heterogeneity of the present meta-analysis, limiting its accuracy. Xu et al. [13] performed a single center study of 100 patients with gastric cancer who had received TLTG. Of the 100 patients, one patient experienced anastomotic leakage (1\%). They found the Endo Bulldog Clamp to be tightly clipped and potential due to the ischemia of the EJ anastomotic method. Cases of anastomotic leakage were found to be serious. Several studies have shown that cases of anastomotic leakage account for 0 to $7.6 \%$, while cases of anastomotic stricture account for 0 to $4.8 \%$. These results are consistent with those of our study (differ from those of our study). Morimoto et al.[15] performed a study of 77 patients and found anastomotic leakage occurs in $2.6 \%$ of cases. Several studies show that intracorporeal EJ involves applying circular-stapled methods such as side-to-side, functional end-to-end, and end-to-side methods[14, 16-20]. Several EJ methods have be proven safe and feasible to use [13,15-19].

Several factors render laparoscopic EJs difficult to apply. An anastomotic EJ is positioned within the upper abdomen to restrict the diaphragm crus. This can complicate an anastomotic EJ. Additionally, the anastomotic esophagus naturally retracts to the mediastinum, further complicating EJ anastomosis procedures. SoKo et al.[12] reported that the extensive mobilization of the distal esophagus reduces anastomotic tension. They reported a lower incidence of anastomotic cases, namely, 0 cases. This may be related to low levels of anastomotic tension and to the limited mobilization of the distal esophageal. A limited hiatal field does not provide enough space for EJ anastomosis execution. Patients have different BMls, and particularly, an adequate anastomotic location is challenging in obese patients. Some centers have adopted an extra-operative EJ anastomosis with mini laparotomy to ensure better anastomotic outcomes, particularly for overweight patients. This technique involves the extensive dissection of the distal esophagus and crura, which can increase risks of bleeding and of further hiatal hernia development. Additionally, Norero et al.[10] found that a hand-sewn EJ anastomosis involves less crura and distal esophagus dissection and allows for the EJ placement at or below the crura.

Furthermore, the use of circular staplers presents additional challenges, including technical difficulties associated with the positioning of the stapler anvil. While systems of transoral anvil delivery have been developed, which can damage esophageal mucosa and can cause bacterial infections of the abdominal cavity[21].

The anastomotic stricture rate is $1 \% 95 \% \mathrm{Cl} 0$ to $3 \%$. Xu et al.[13] conducted a study of 100 patients with a stricture value of 0 . Liu et al. [22] also performed intracorporeal circular stapled esophagojejunostomy using a conventional purse-string suture instrument after laparoscopic total gastrectomy.

Norero et al.[10] found a higher EJ stenosis value (3.9\%) than we did through our study. The use of linear staplers for EJ purposes has been examined Chen et al. and Inaba et al. During EJ anastomosis procedures, they found that lateral-lateral EJ movement made using a linear stapler can increase tension levels, leading to anastomotic leakage complications. Bracale et al.[9] conducted a multicenter study of 56 patients and found an anastomotic stricture value of $3 \%$, echoing the literature showing values of 3 to $10 \%$ resulting from circular stapler use [23-25]. The same authors also reported on a form of anastomosis similar to that described above but involving an isoperistaltic jejunal loop. When applying this technique, the rate of anastomotic leakage (6\%) observed does not differ considerably from that described in the literature. Higher rates of $12.8 \%$ have been reported from mixed surveys (stapler and manual approaches) and rates of $3-5 \%$ have been reported from surgeries performed with a circular stapler. From eight total laparoscopic gastrectomies Huscher et al.[4] did not observe leakage or stenosis resulting from the use of side-to-side EJS methods.

Regarding intraluminal bleeding, several studies have reported similar, higher or lower values relative to those of our study. This may be related varying levels of familiarity with suturing tasks among professionals.

Our study presents several limitations. The considered studies are first not focused on RCTs, and a small sample of studies was considered, which may have reduced the quality of our results. Additionally, the considered studies present signs of selection bias, are not based on quantitative data, and do not focus on survival outcomes.

\section{Conclusions}

TLTG methods involving the use of intracorporeal hand-sewn esophagojejunostomy are safe methods for the treatment of gastric cancer. At present, the reported anastomosis method and TLTG approach more generally should only be applied in high-volume laparoscopic surgical centers. 
Declarations

\section{Abbreviations}

Esophagojejunostomy: EJ; totally laparoscopic total gastrectomy: TLTG; estimate: ES

\section{Acknowledgements}

Not applicable.

\section{Funding}

\section{No funding was received.}

\section{Availability of data and materials}

Data sharing not applicable to this article as no datasets were generated or analysed during the current study.

\section{Authors' contributions}

YLJ and YCZ designed the study. YLJ wrote the manuscript. YLJ and YCZ analyzed the data. YCZ and YLJ searched the articles. All authors read and approved the final manuscript.

\section{Ethics approval and consent to participate}

Not applicable.

\section{Consent for publication}

Not applicable.

\section{Competing interest}

\section{The authors declare that they have no conflict of interests.}

\section{Author details}

1.School of Medicine, Hang Zhou Normal University, Hangzhou, China 2.Department of Gastrointestinal and Pancreatic Surgery, Zhejiang Provincial People's Hospital, Key Laboratory of Gastroenterology of Zhejiang Province, People's Hospital of Hangzhou Medical College, 158 Shangtang Road, Hangzhou 310014, Zhejiang Province, China

\section{References}

1.Ferlay J, Shin HR, Bray F, Forman D, Mathers C, Parkin DM. Estimates of worldwide burden of cancer in 2008: GLOBOCAN 2008. International journal of cancer. 2010;127(12):2893-917. 
2.Jemal A, Center MM, DeSantis C, Ward EM. Global patterns of cancer incidence and mortality rates and trends. Cancer epidemiology, biomarkers \& prevention: a publication of the American Association for Cancer Research, cosponsored by the American Society of Preventive Oncology. 2010;19(8):1893-907.

3.Kitano S, Iso Y, Moriyama M, Sugimachi K. Laparoscopy-assisted Billroth I gastrectomy. Surgical laparoscopy \& endoscopy. 1994;4(2):146-8.

4.Huscher CG, Mingoli A, Sgarzini G, Sansonetti A, Di Paola M, Recher A, et al. Laparoscopic versus open subtotal gastrectomy for distal gastric cancer: five-year results of a randomized prospective trial. Annals of surgery. 2005;241(2):232-7.

5.Vinuela EF, Gonen M, Brennan MF, Coit DG, Strong VE. Laparoscopic versus open distal gastrectomy for gastric cancer: a meta-analysis of randomized controlled trials and high-quality nonrandomized studies. Annals of surgery. 2012;255(3):446-56.

6.Kim W, Kim HH, Han SU, Kim MC, Hyung WJ, Ryu SW, et al. Decreased Morbidity of Laparoscopic Distal Gastrectomy Compared With Open Distal Gastrectomy for Stage I Gastric Cancer: Short-term Outcomes From a Multicenter Randomized Controlled Trial (KLASS-01). Annals of surgery. 2016;263(1):28-35.

7.Shim JH, Yoo HM, Oh SI, Nam MJ, Jeon HM, Park CH, et al. Various types of intracorporeal esophagojejunostomy after laparoscopic total gastrectomy for gastric cancer. Gastric cancer: official journal of the International Gastric Cancer Association and the Japanese Gastric Cancer Association. 2013;16(3):420-7.

8.Zheng XY, Pan Y, Chen K, Gao JQ, Cai XJ. Comparison of Intracorporeal and Extracorporeal Esophagojejunostomy after Laparoscopic Total Gastrectomy for Gastric Cancer: A Meta-Analysis Based on Short-Term Outcomes. Chinese medical journal. 2018;131(6):713-20.

9.Bracale U, Marzano E, Nastro P, Barone M, Cuccurullo D, Cutini G, et al. Side-to-side esophagojejunostomy during totally laparoscopic total gastrectomy for malignant disease: a multicenter study. Surgical endoscopy. 2010;24(10):2475-9.

10.Norero E, Munoz R, Ceroni M, Manzor M, Crovari F, Gabrielli M. Two-Layer Hand-Sewn Esophagojejunostomy in Totally Laparoscopic Total Gastrectomy for Gastric Cancer. Journal of gastric cancer. 2017;17(3):267-76.

11.Puntambekar S, Badran R, Parikh H, Bansal A, Sharma V, Chitale M, et al. Technical Feasibility and Short-Term Outcome of Intracorporeal Hand-Sewn Esophagojejunostomy After Laparoscopic Total Gastrectomy: Our Experience. The Indian journal of surgery. 2017;79(6):497-503.

12.So KO, Park JM. Totally Laparoscopic Total Gastrectomy Using Intracorporeally Hand-Sewn Esophagojejunostomy. Journal of gastric cancer. 2011;11(4):206-11.

13.Xu X, Huang C, Mou Y, Zhang R, Pan Y, Chen K, et al. Intra-corporeal hand-sewn esophagojejunostomy is a safe and feasible procedure for totally laparoscopic total gastrectomy: short-term outcomes in 100 consecutive patients. Surgical endoscopy. 2018;32(6):2689-95.

14.Du J, Shuang J, Li J, Li J, Hua J. Intracorporeal circular-stapled esophagojejunostomy after laparoscopic total gastrectomy: a novel self-pulling and holding purse-string suture technique. Journal of the American College of Surgeons. 2014;218(3):e67-72.

15.Morimoto M, Kitagami H, Hayakawa T, Tanaka M, Matsuo Y, Takeyama $\mathrm{H}$. The overlap method is a safe and feasible for esophagojejunostomy after laparoscopic-assisted total gastrectomy. World journal of surgical oncology. 2014;12:392.

16.Okabe H, Satoh S, Inoue H, Kondo M, Kawamura J, Nomura A, et al. Esophagojejunostomy through minilaparotomy after laparoscopic total gastrectomy. Gastric cancer: official journal of the International Gastric Cancer Association and the Japanese Gastric Cancer Association. 2007;10(3):176-80.

17.Inaba K, Satoh S, Ishida Y, Taniguchi K, Isogaki J, Kanaya S, et al. Overlap method: novel intracorporeal esophagojejunostomy after laparoscopic total gastrectomy. Journal of the American College of Surgeons. 2010;211(6):e25-9.

18.Okabe H, Obama K, Tsunoda S, Tanaka E, Sakai Y. Advantage of completely laparoscopic gastrectomy with linear stapled reconstruction: a long-term follow-up study. Annals of surgery. 2014;259(1):109-16.

19.Matsuda T, Iwasaki T, Mitsutsuji M, Hirata K, Maekawa Y, Tsugawa D, et al. Surgical outcomes of intracorporeal circular-stapled esophagojejunostomy using modified over-and-over suture technique in laparoscopic total gastrectomy. Surgical endoscopy.

Page 6/12 
20.Sakuramoto S, Kikuchi S, Futawatari N, Moriya H, Katada N, Yamashita K, et al. Technique of esophagojejunostomy using transoral placement of the pretilted anvil head after laparoscopic gastrectomy for gastric cancer. Surgery. 2010;147(5):742-7.

21.Kim JH, Choi Cl, Kim DI, Kim DH, Jeon TY, Kim DH, et al. Intracorporeal esophagojejunostomy using the double stapling technique after laparoscopic total gastrectomy: A retrospective case-series study. World journal of gastroenterology. 2015;21(10):2973-81.

22.Liu W, Guo Y, Qiu Z, Niu D, Zhang J. Intracorporeal Circular Stapled Esophagojejunostomy Using Conventional Purse-String Suture Instrument After Laparoscopic Total Gastrectomy. Journal of laparoendoscopic \& advanced surgical techniques Part A.

2017;27(12):1299-304.

23.Fujimoto S, Takahashi M, Endoh F, Takai M, Kobayashi K, Kiuchi S, et al. Stapled or manual suturing in esophagojejunostomy after total gastrectomy: a comparison of outcome in 379 patients. American journal of surgery. 1991;162(3):256-9.

24.West PN, Marbarger JP, Martz MN, Roper CL. Esophagogastrostomy with the EEA stapler. Annals of surgery. 1981;193(1):76-81.

25.Sannohe Y, Hiratsuka R, Doki K. Single layer suture by manual or mechanical stapling technique in esophagojejunostomy after total gastrectomy. American journal of surgery. 1981;142(3):403-6.

\section{Tables}

Table 1. Basic Characteristics of the Included Studies

\begin{tabular}{|c|c|c|c|c|c|c|}
\hline Study & Study type & Sample Size & ASA score & Male/Female & $\begin{array}{l}\text { Age } \\
\text { (Mean years) }\end{array}$ & $\begin{array}{l}\text { BMI } \\
\left(\mathrm{Kg} / \mathrm{m}^{2}\right)\end{array}$ \\
\hline $\mathrm{Xu2017}$ & retrospective & 100 & 61 & $83 / 17$ & 65 & 23 \\
\hline Norero2017 & retrospective & 51 & 24.13 & $27 / 24$ & 60 & 25 \\
\hline Puntambekar2016 & retrospective & 30 & 1.4 & $11 / 19$ & 49.9 & 22.4 \\
\hline SoKo2011 & retrospective & 6 & 2.2 & $6 / 0$ & 66.5 & 24.6 \\
\hline Bracale2010 & retrospective & 67 & 1.9 & $45 / 22$ & 66.9 & 1.7 \\
\hline
\end{tabular}

Table 2 Quality assessment of the included studies

\begin{tabular}{|c|c|c|c|c|c|c|c|c|c|c|c|}
\hline \multirow[t]{2}{*}{ Study } & \multicolumn{2}{|c|}{ Design } & \multicolumn{4}{|c|}{ Selection } & \multirow[t]{2}{*}{ Comparability } & \multicolumn{3}{|c|}{ Outcome } & \multirow[t]{2}{*}{ Total } \\
\hline & & & $\begin{array}{l}\text { Representativeness } \\
\text { of exposed cohort }\end{array}$ & $\begin{array}{c}\text { Selective of } \\
\text { nonexposed } \\
\text { Cohort }\end{array}$ & $\begin{array}{l}\text { Ascertainment } \\
\text { of exposure }\end{array}$ & $\begin{array}{l}\text { Outcome } \\
\text { not } \\
\text { present } \\
\text { at start }\end{array}$ & & $\begin{array}{l}\text { Assessment } \\
\text { of outcome }\end{array}$ & $\begin{array}{l}\text { Adequate } \\
\text { follow-up } \\
\text { length }\end{array}$ & $\begin{array}{c}\text { Adequacy } \\
\text { of follow- } \\
\text { up }\end{array}$ & \\
\hline Sol & & $\mathrm{R}$ & $*$ & * & & $*$ & & * & $*$ & * & 6 \\
\hline Brac & & $\mathrm{R}$ & $*$ & * & $*$ & $*$ & & $*$ & $*$ & $*$ & 7 \\
\hline Puntan & ekar & $\mathrm{R}$ & $*$ & $*$ & $*$ & $*$ & & $*$ & $*$ & * & 7 \\
\hline Nor & & $\mathrm{R}$ & $*$ & $*$ & $*$ & $*$ & & $*$ & $*$ & * & 7 \\
\hline $\mathrm{X}$ & & $\mathrm{R}$ & $*$ & $*$ & $*$ & $*$ & & $*$ & $*$ & $*$ & 7 \\
\hline
\end{tabular}

Table2 Newcastle-Ottawa Scale for risk of bias assessment of the included studies

$R$ Respectively study 


\section{Figures}

Flow diagram of the process for the selection of relevant studied

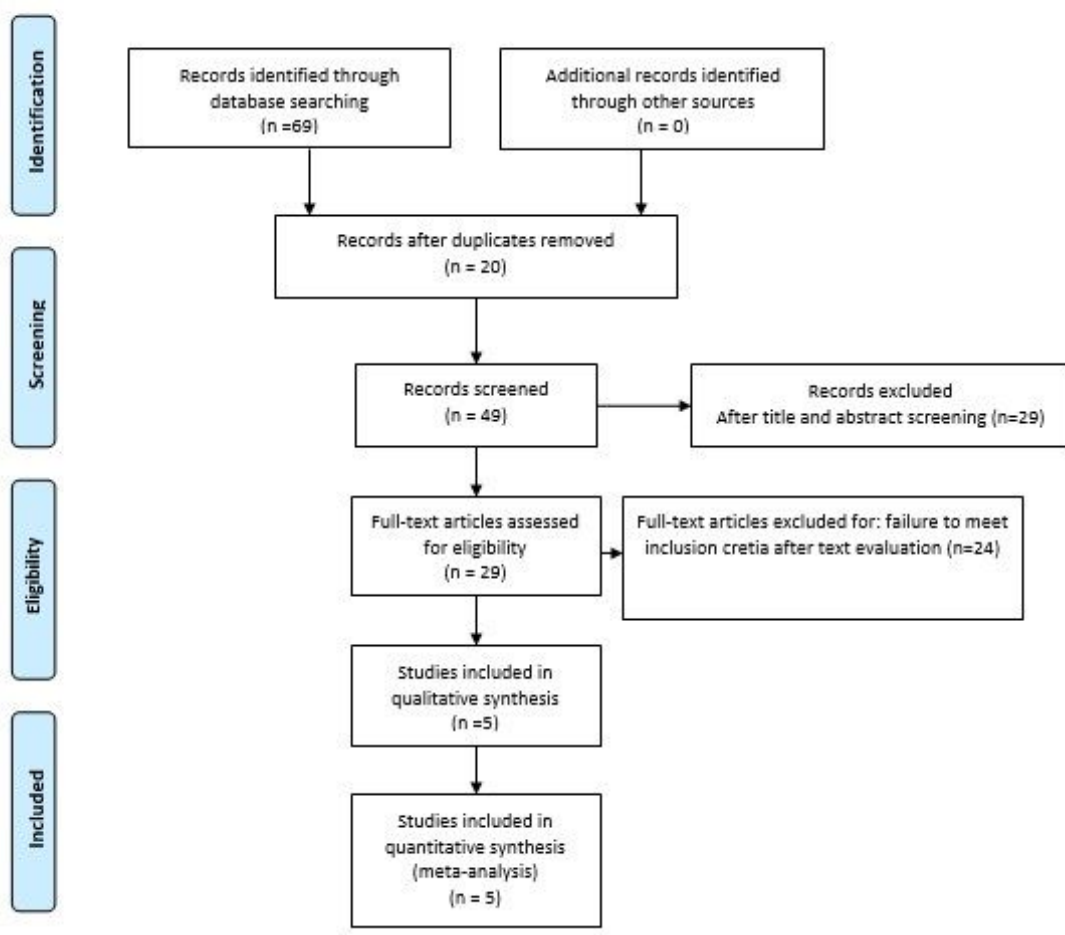

Figure 1

Flow diagram of the process for the selection of relevant studies. 


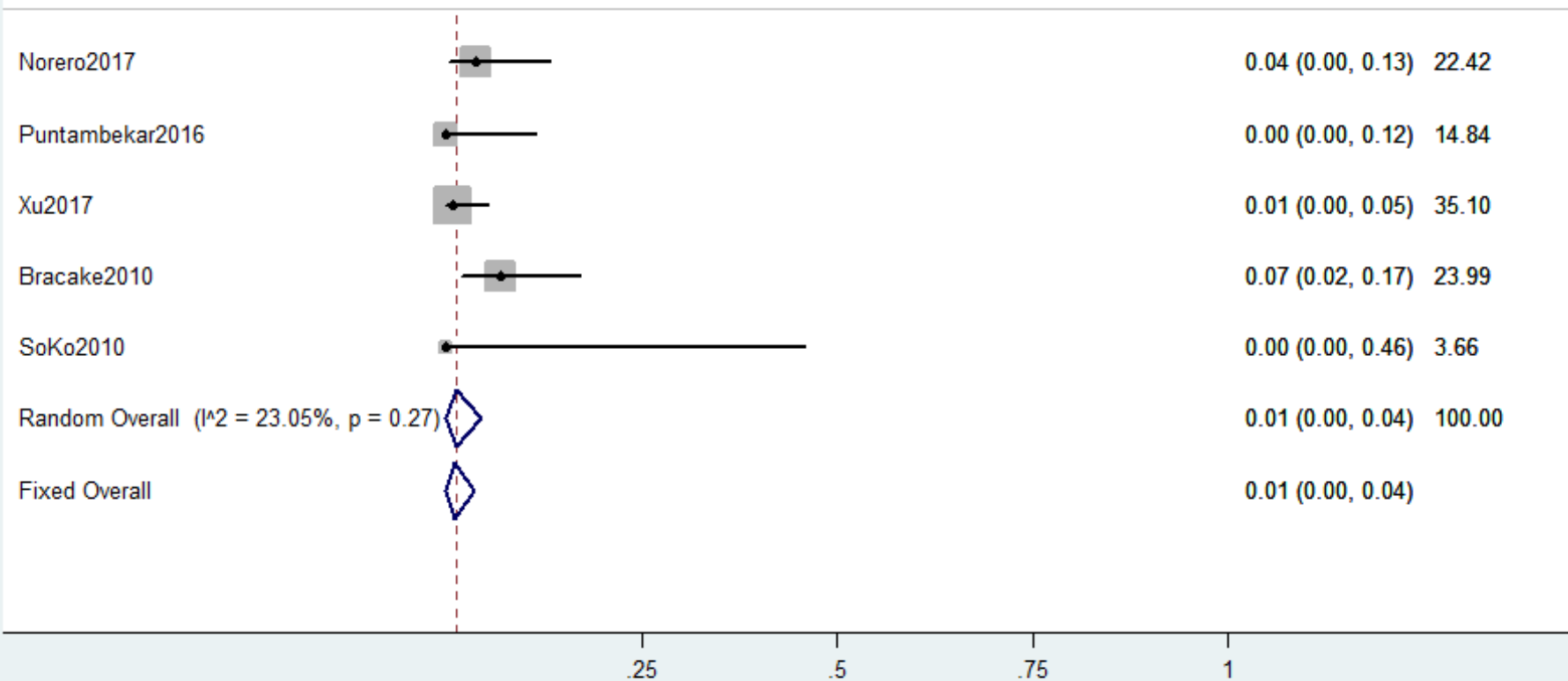

\section{Figure 2}

Forest plot for anastomotic leakage. 


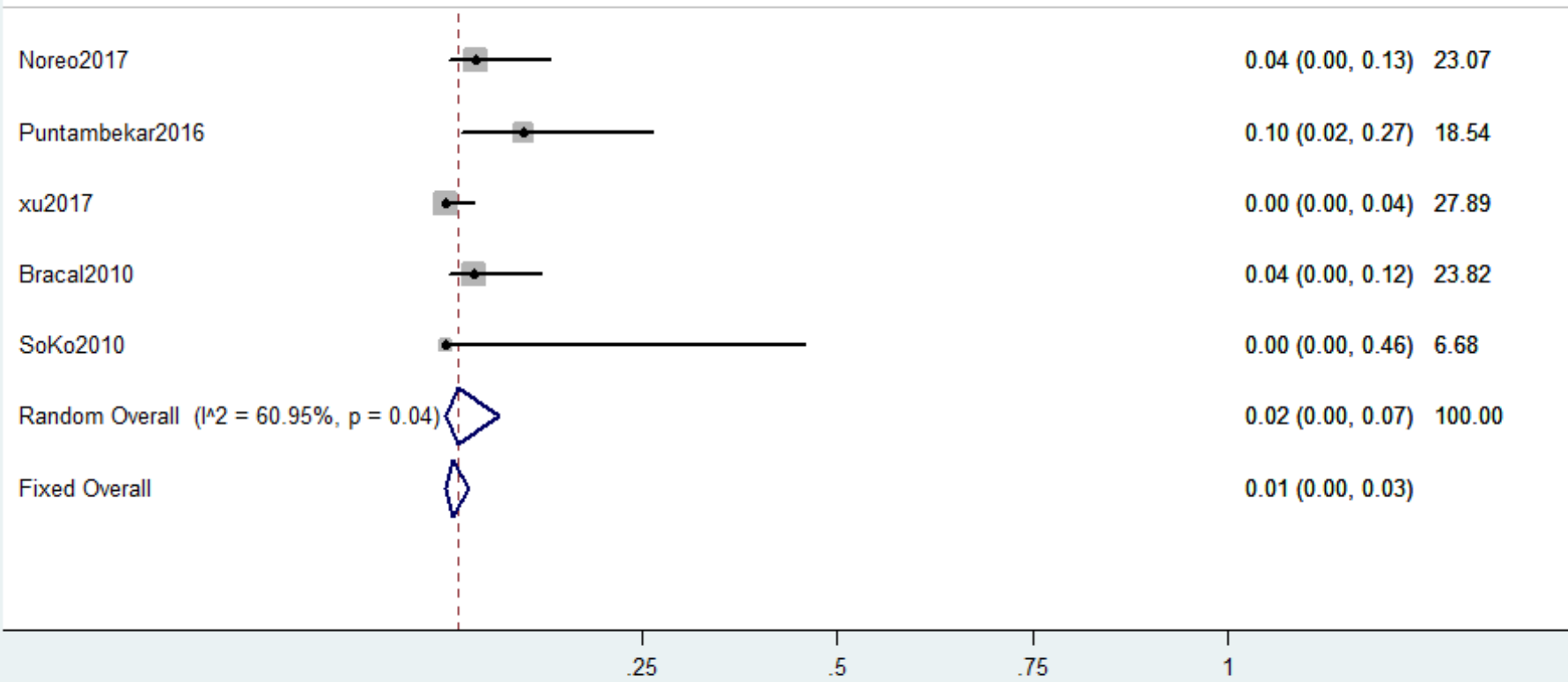

\section{Figure 3}

Forest plot for anastomotic stricture. 


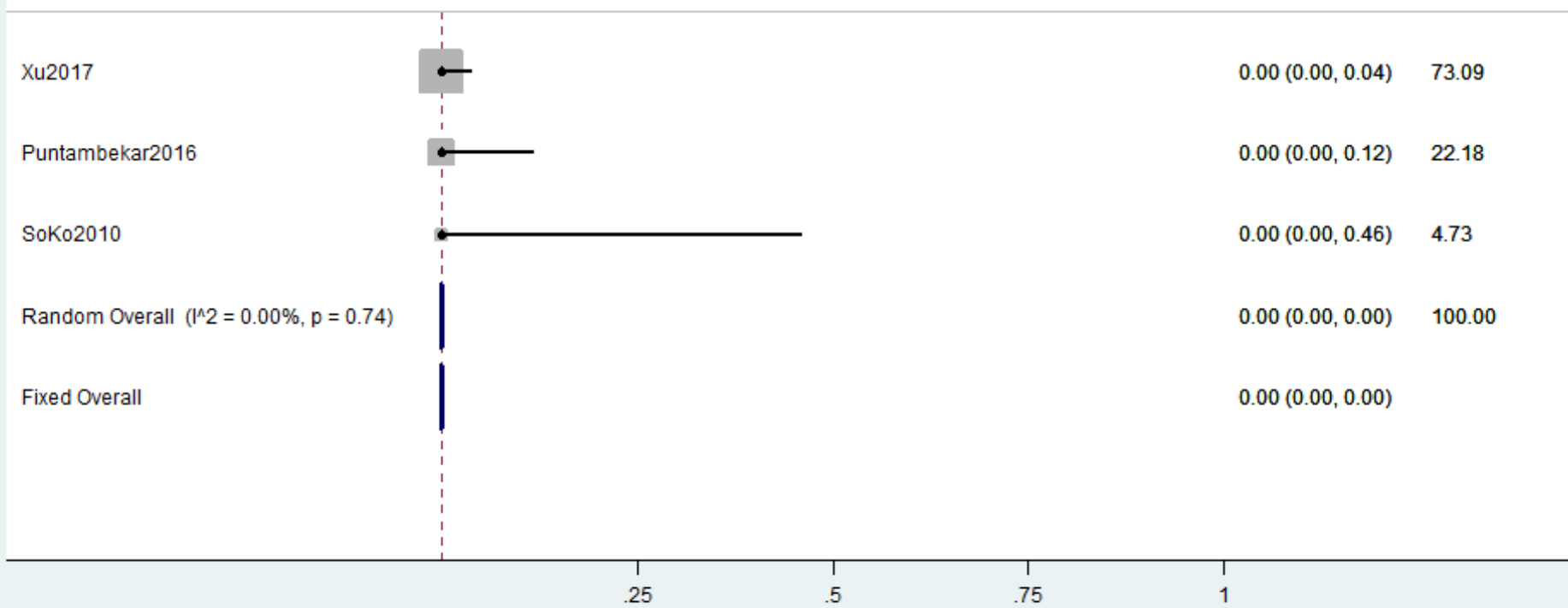

\section{Figure 4}

Forest plot for conversion. 


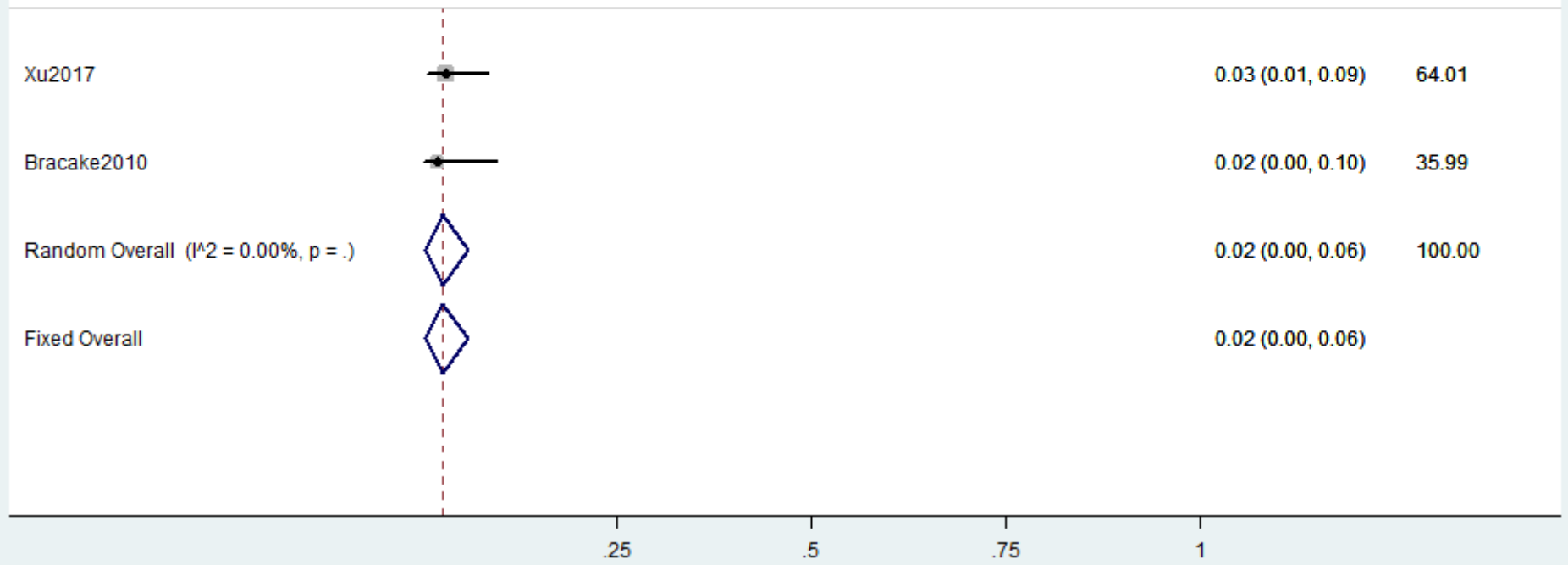

\section{Figure 5}

Forest plot for postoperative bleeding. 